\title{
Toward a Theory of Learner-Centered Training Design: An Integrative Framework of Active Learning
}

\author{
Bradford S. Bell \\ Cornell University
}

Steve W. J. Kozlowski

Michigan State University

The dynamicity and complexity of the current business landscape mean that, now more than ever, organizations must rely on workplace learning and continuous improvement to gain and sustain competitive advantage (Salas \& Cannon-Bowers, 2001). However, the same trends that are driving the renewed emphasis on workplace learning have also introduced new training challenges. Traditionally, training has focused on developing routine expertise, or providing employees with competencies that directly transfer to the job. Yet, the changing nature of work has increasingly shifted attention toward the development of adaptive expertise, or competencies that are not only specialized but also flexible enough to be modified to changing circumstances. Although our understanding of how to develop adaptability remains limited, emerging research suggests that training designs that selectively influence cognitive, motivational, and affective self-regulatory processes to induce an active approach to learning may hold promise for developing adaptive capabilities (for a review, see Kozlowski, Toney, et al., 2001, and chapters by Mayer and CannonBowers \& Bowers, this volume).

Companies also face the challenge of delivering training on demand and to a workforce that is increasingly distributed across the globe. The result has been a steady increase in the utilization of e-learning because of its capacity to deliver just-in-time training to employees anytime and almost anywhere. For example, in 2004 nearly $58 \%$ of all training days at IBM were conducted through e-learning, and the company's on-demand learning database has grown to include 54,000 courses. One important 
implication of putting training online is that employees are being given unprecedented control over their learning (Bell \& Kozlowski, 2002). As Brown and Ford (2002) stated, "[O]nce the computer program is set up, the burden for active learning switches to the learner" (p. 194). Yet, research has consistently demonstrated that many learners do not make good use of this control (DeRouin, Fritzsche, \& Salas, 2004). This creates a training dilemma and highlights the need for strategies that can help employees effectively leverage the control offered by online training programs.

There is also an emerging trend within organizations of replacing formal, classroom training with more informal, job-embedded training. As Kozlowski, Toney, et al. (2001) stated, "It [training] is shifting from an offsite single episode to a systematic series of learning experiences that are integrated in the workplace and embedded in work technology" (p. 60; italics in original). Integrated-embedded training has the potential to offer many advantages, including improved efficiency and cost control as well as enhanced transfer of competencies from training to the workplace. However, embedded training is often more informal and self-directed, which places greater responsibility on employees to manage their own learning. It is essential, therefore, to understand the process of selfdirected learning and identify instructional strategies that can be used to help support employees' learning activities outside the classroom. As Salas and Cannon-Bowers (2001) noted, there is a need for research "that helps us get a better understanding of what, how, and when on-the-job training works" (p. 491).

A key theme that underlies developments in the areas of adaptive expertise, technology-based training, and embedded training is the inherent shift from a traditional, proceduralized approach to training, which tends to treat the trainee as a passive recipient of information, to a learner-centered approach that makes the learner an active participant in the learning process-an active learning approach. The active learning approach aims to stimulate and shape a combination of cognitive, motivational, and emotion self-regulatory processes that characterize how people focus their attention, direct their effort, and manage their emotions during learning (Kozlowski, Toney, et al., 2001). Recent research indicates that these self-regulatory processes may play a critical role not only in the development of adaptive expertise but also in enabling individuals to successfully navigate learner-controlled training contexts, such as e-learning and informal, on-the-job training (DeRouin et al., 2004; Ivancic \& Hesketh, 2000). Although a number of discrete active learning interventions have been developed and tested over the past decade, with few exceptions (Clark, 2001; Mayer, this volume) very little work has integrated across these interventions to identify their common training components and the process pathways by which they exert effects on learning outcomes. 
As a result, our understanding of the active learning approach and how to leverage it to address these emerging challenges remains limited.

The goal of this chapter, therefore, is to develop an integrative conceptual framework of active learning, and we do this by focusing on three primary issues. First, we define the active learning approach and contrast it to more traditional, passive instructional approaches. We argue that the active learning approach can be distinguished from not only more passive approaches to instruction but also other forms of experiential learning based on its use of formal training components to systematically influence trainees' cognitive, motivational, and emotion self-regulatory processes. Second, we examine how specific training components can be used to influence each of these process domains. Through a review of prior research, we extract core training components that cut across different active learning interventions, map these components onto specific process domains, and consider the role of individual differences in shaping the effects of these components (aptitude-treatment interactions [ATIs]). A final issue examined in this chapter concerns the outcomes associated with the active learning approach. Despite its considerable versatility, the active learning approach is not the most efficient or effective means of responding to all training needs. Thus, we discuss the impact of the active learning approach on different types of learning outcomes in order to identify the situations under which it is likely to demonstrate the greatest utility. We conclude the chapter by highlighting research and practical implications of our integrated framework, and we outline an agenda for future research on active learning.

\section{Theoretical Foundation of the Active Learning Approach}

Prior research has typically conceptualized the active learning approach by comparing it to more passive approaches to learning, which some refer to as transmission or conduit models of learning (Iran-Nejad, 1990; Schwartz \& Bransford, 1998). The active learning approach is distinct in two fundamental respects. First, the active learning approach provides individuals with significant control over their learning. Whereas passive approaches to learning have the instructional system (e.g., the instructor, or the computer program) assume most of the responsibility for important learning decisions, the active learning approach gives the learner primary responsibility for managing his or her learning (e.g., sequencing his or her learning activities, monitoring, and judging progress). The important distinction is one of internal versus external regulation of learning (Iran-Nejad, 1990). 
Second, the active learning approach is grounded in the constructivist vision of learning, which argues that learning is an inductive process in which individuals explore and experiment with a task to infer the rules, principles, and strategies for effective performance (Mayer, 2004; Smith, Ford, \& Kozlowski, 1997). In contrast, passive approaches to learning are based on conduit or transmission models of learning, which assume that individuals acquire knowledge by having it transmitted to them by some external source (e.g., a teacher or text) (Schwartz \& Bransford, 1998). The important distinction is one of active knowledge construction versus the internalization of external knowledge.

The notion that the learner should be actively involved in the learning process is not exclusive to the active learning approach; it is a theme that can be found in a number of educational philosophies and approaches, including experiential learning and action learning (Kolb, 1984; Revans, 1982). However, the active learning approach is unique in that it extends beyond simply "learning by doing" and utilizes formal training components to systematically shape and support trainees' learning processes. In particular, the active learning interventions that have been developed in recent years, such as error training, mastery training, and guided exploration, combine multiple training components intended to selectively influence the nature, quality, and focus of self-regulatory activity (Debowski, Wood, \& Bandura, 2001; Keith \& Frese, 2005; Kozlowski, Gully, et al., 2001; Kozlowski, Toney, et al., 2001). Self-regulation can be defined as processes "that enable an individual to guide his/her goal directed activities over time and across changing circumstances," including the "modulation of thought, affect, behavior, or attention" (Karoly, 1993, p. 25). Although previous research has shown that active learning interventions can enhance important learning outcomes, particularly adaptive transfer, it has not provided much insight into the self-regulatory mechanisms through which these interventions have their effects. One reason is that very little of this work has attempted to directly test these mechanisms (Keith \& Frese, 2005). Moreover, in the few cases where processes have been modeled, the focus on multifaceted active learning interventions makes it difficult to precisely map pathways between the training components that comprise these interventions and the process targets (Kozlowski \& Bell, 2006).

Thus, a primary goal of the current chapter is to identify the core training components that comprise active learning interventions and more clearly elucidate the process pathways through which these components have their effects. In the following section, we use the Adaptive Learning System (ALS) framework developed by Kozlowski, Toney, et al. (2001) to highlight the role that training design can play in shaping trainee selfregulation. The ALS was developed as a theoretically based model to guide the design of training interventions that actively and selectively stimulate self-regulatory processes as a means to enhance learning, 
performance, and performance adaptation. Although the model is application oriented, it serves as a useful theoretical framework for examining how the training components embedded in active learning interventions may influence relatively distinct self-regulatory pathways to drive training effectiveness. The different elements of the ALS framework are presented in Figure 8.1 and discussed below.

\section{The ALS}

\section{Self-Regulation System}

At the core of the ALS is the dynamic process of self-regulation. In training contexts, the self-regulatory system can be divided into three general domains. The first, practice behaviors, defines what individuals do during training. The primary focus is on how individuals allocate effort (i.e., motivation) during practice aimed at skill improvement, although one should not overlook pre- and postpractice behaviors such as studying, strategic planning, and reviewing feedback, which are equally important forms of effort allocation (Cannon-Bowers, Rhodenizer, Salas, \& Bowers, 1998). The second domain, self-monitoring, represents the cognitive component of the self-regulation system. It is concerned with how trainees focus their cognitive attention and reflect on their progress toward desired objectives (Carver \& Scheier, 1990; Karoly, 1993). The final self-regulatory component highlighted in the model is self-evaluation reaction, which focuses on trainees' affective (i.e., emotion-based) reactions to goal progress. Kozlowski, Toney, et al. (2001) highlighted two primary aspects of self-reactions critical in learning contexts: self-efficacy and causal attributions. High levels of self-efficacy and appropriate attributions are essential if self-regulatory activities are to be engaged or maintained (Kanfer \& Ackerman, 1989).

\section{Training Strategy}

A training strategy is composed of specific training components that form a training intervention. That is, interventions are constructed from a combination of manipulations designed to actively leverage the different domains of the self-regulation system discussed above. Kozlowski, Toney, et al. (2001) reviewed three primary training components. First, training design refers to the nature of the experience that is created for the trainee through the provision of information and type of practice available during learning. Some of the training design features that have been shown to have important implications for self-regulation during learning 


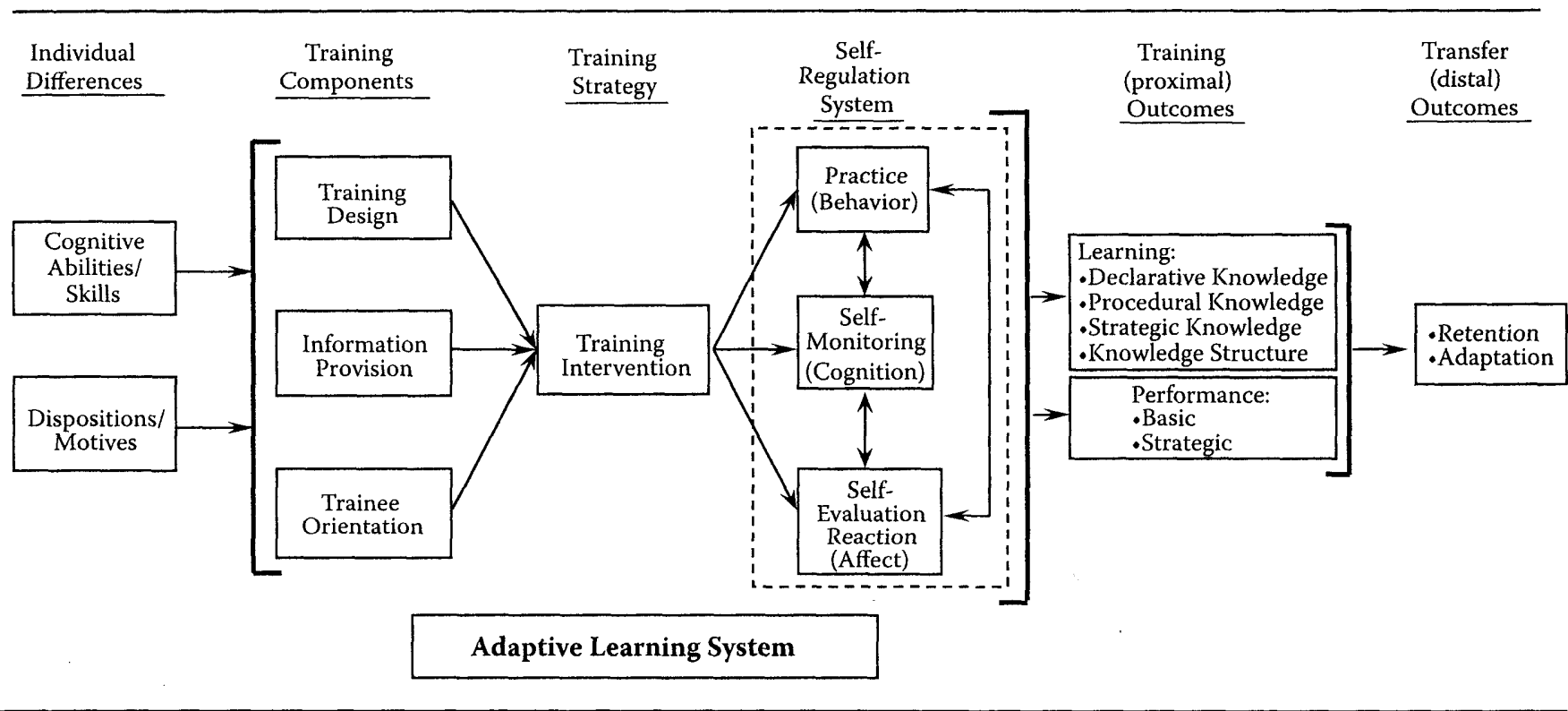

\section{FIGURE 8.1}

Theoretical model of adaptive learning design. (From Kozlowski, S. W. J., Toney, R. J., Mullins, M. E., Weissbein. D. A., Brown, K. G., \& Bell, B. S. (2001). Developing adaptability: A theory for the design of integrated-embedded training systems. In E. Salas (Ed.), Advances in human performance and cognitive engineering research (Vol. 1, pp. 59-123). Amsterdam: JAI/Elsevier Science. (C 1999, 2006 by S. W. J. Kozlowski. All rights reserved worldwide. Adapted and used with permisison.) 
include the sequencing and pacing of training (Kozlowski \& Bell, 2006) and errors during learning (Frese et al., 1991). Information provision refers to the feedback provided to trainees that influences their interpretation of past progress. There are many conditions that influence how feedback impacts learning, including the type of feedback given (e.g., descriptive vs. normative), trainees' ability and performance levels, and feedback sign (i.e., positive or negative; Kluger \& DeNisi, 1996). In addition to feedback, information provision refers to guidance provided to trainees that can be designed to influence their preparation for future learning efforts (Bell \& Kozlowski, 2002). The final training component is trainee orientation, or the motivational and attributional frames that affect the way the trainee perceives the training experience. The type of orientation an individual adopts in an achievement situation is influenced by both dispositional and situational influences that are independent and additive (Archer, 1994; Boyle \& Klimoski, 1995; Chen, Gully, Whiteman, \& Kilcullen, 2000). The situational factors that drive trainees' motivational orientation can be divided into two categories: instructional goals and general training frames. Instructional goals are the explicit directions provided to trainees, whereas general training frames do not focus explicitly on goals or objectives, but rather are general statements made by trainers that influence trainees' goal orientation. Goals and training frames that emphasize learning and task mastery, as opposed to performance and the demonstration of competence, can enhance self-regulation, learning, and adaptability (Kozlowski \& Bell, 2006; Kozlowski, Gully, et al., 2001).

\section{Training Outcomes}

Through its effects on the self-regulation system, training strategy exerts an influence on multidimensional training outcomes (Kraiger, Ford, \& Salas, 1993). Proximal training outcomes are outcomes that arise directly from training and are exhibited immediately at its completion. Kozlowski, Toney, et al. (2001) argued that these outcomes can be divided into two categories: learning and performance. Learning outcomes represent the more abstract cognitive indicators of learning, such as different types of knowledge (e.g., declarative or strategic) and knowledge organization. Performance outcomes reflect the behavioral manifestations of learning. The performance domain can be further divided into basic and strategic performance (Bell \& Kozlowski, 2002). Basic performance captures the information-processing and decision-making aspects of a task domain, whereas strategic performance involves the more complex behavioral routines that underlie adaptability to dynamic task environments.

These proximal training outcomes affect trainees' ability to transfer what they have learned to tasks that occur following training. Transfer can be broken down into two main types: near (or analogical) and far 
(or adaptive) transfer. Near transfer represents the transfer of skills to problems similar to those encountered in training (Frese, 1995). Far transfer, however, "involves using one's existing knowledge base to change a learned procedure, or to generate a solution to a completely new problem" (Ivancic \& Hesketh, 2000, p. 1968). Some training strategies are better suited than others for promoting far transfer, based on their ability to stimulate specific self-regulatory patterns that lead to the development of strategic knowledge and skills, which underlie adaptability (Bell \& Kozlowski, 2008; Keith \& Frese, 2005).

\section{Individual Differences}

Finally, the different abilities and dispositional tendencies that individuals bring with them to the training setting are also important. We know that a number of individual differences, including cognitive ability, goal orientation, anxiety, and locus of control, directly influence learning outcomes (Colquitt, LePine, \& Noe, 2000). Yet, the low degree of structure and the lack of external guidance that often characterize technology-based and informal training programs suggest that individual differences may be particularly potent in these contexts (Brown, 2001). Accordingly, it is important to understand how both cognitive abilities and motivation- and emotionbased traits interact with different training strategies to impact the process and outcomes of active learning (Gully, Payne, Kiechel, \& Whiteman, 2002; Keith \& Frese, 2005). To the extent that we can more precisely map these potential ATIs, we will advance our understanding of how to design training to more effectively meet the needs of different learners.

\section{Application of the ALS}

The ALS is predicated on developing training interventions that systematically influence self-regulatory processes to facilitate learning and performance. In that function, the model and approach have been effective. For example, Kozlowski, Gully, et al. (2001) used the model to develop a mastery training strategy composed of multiple training components, including learning goals, a mastery-oriented training frame, and the progressive sequencing of knowledge and skill development. Kozlowski, Gully, et al. found that the mastery training strategy not only had a positive impact on trainees' self-efficacy but also led to greater and more coherent knowledge, better training performance, and enhanced adaptability. Bell and Kozlowski (2002) also used the ALS model to develop an adaptive guidance intervention, which leverages the information provision component of the model to support trainees' self-regulatory processes in learnercontrolled, online training environments. Specifically, adaptive guidance 
assesses trainees' learning in real time and provides personalized study and practice recommendations. Bell and Kozlowski (2002) found that this supplemental information not only enhanced trainees' self-regulation (e.g., self-efficacy, and attentional focus) but also facilitated learning and adaptive transfer.

\section{Elaborating the Training Components and Process Pathways of Active Learning}

The studies by Kozlowski, Gully, et al. (2001) and Bell and Kozlowski (2002) demonstrate the value of the ALS as a guiding framework for the design of effective training interventions. However, one limitation associated with studying complex, multifaceted interventions is that it is difficult or impossible to isolate the effects of specific training components or to identify the process pathways through which they operate. For example, in the Kozlowski, Gully, et al. study described above, it is unclear which of the different training components (e.g., learning goals, mastery-oriented training frame, and/or goal proximity) account for the effects of the mastery training strategy. The results may be explained by a single component, the independent additive contributions of several components, or the interactive effects of two or more of the components; we do not know. Further, one is unable to compare the relative impact of the different components on specific learning processes and outcomes, which is critical information for designing future strategies that will be optimally efficient and effective. Last, decomposing a complex intervention allows one to isolate the precise processes or mechanisms by which specific training components exert their effects. For example, Kozlowski, Gully, et al. (2001) examined several self-regulatory variables as mediators of the effects of their mastery training strategy. However, because the training components embedded in this strategy were not teased apart, it is impossible to align different process pathways with specific training components.

To begin to address these research gaps, a recent study by Kozlowski and Bell (2006) sought to tease apart the key elements of mastery training. In particular, we examined the independent and integrated effects of three training components drawn from the achievement orientation and goal-setting domains-goal frame (i.e., learning or performance orientation induction), goal content (i.e., tangible learning or performance goals), and goal proximity (i.e., proximal or distal tangible goals) - on trainees' cognitive and affective self-regulatory activities. The results revealed that all three components had significant effects, although goal content was a more potent driver of self-regulatory activity compared to frame or goal proximity. Further, we found that congruent learning frame and content relative to congruent performance frame and content were more beneficial 
for trainees' self-regulatory activity, incongruent combinations of goal frame and content were better than congruent performance frames and content, and effects for the incongruent combinations cutting across the domains were asymmetrical. Finally, we found evidence that distal learning goals were generally more effective for self-regulation than proximal learning goals.

Although this research begins to disentangle the common and distinctive effects of different mastery training components on trainees' self-regulatory activities, it is limited in its narrow focus on only those components embedded in the mastery training strategy and the processes targeted by this strategy. If our goal is to develop a broader theory of active learning, we need to expand our focus and explore the training components and processes that underlie a broader range of active learning interventions. By identifying those areas in which these different interventions converge, we can begin to map the core elements of the active learning approach. In the following section, we present a conceptual framework of active learning, which is aimed at integrating research on different active learning interventions so as to extract a set of core training components and highlight the self-regulatory processes through which these components impact learning and adaptability.

\section{Active Learning: An Integrative Framework}

Our review of several exemplars of the active learning approach revealed three core training components that cut across these interventions. As shown in Table 8.1, these three core training components are the nature of instruction, motivational induction, and emotion control, each of which targets a relatively distinct set of cognitive, motivational, or emotional selfregulatory processes. First, all of these interventions use an exploratory instructional approach to engage learners' cognitive self-regulatory processes, such as metacognition. In some strategies, such as enactive exploration, trainees are provided with very little guidance and are explicitly instructed to explore the task (Heimbeck, Frese, Sonnentag, \& Keith, 2003). In others, such as guided exploration, the emphasis is on more systematic or preplanned exploration (Debowski et al., 2001). Thus, although the level of structure may vary, there is agreement on the use of an exploratory instructional approach to stimulate cognitive self-regulation. Second, most of the interventions incorporate a motivational induction designed to shape the orientation that trainees take toward the training task. As discussed above, trainee orientation can be influenced by both instructional goals and general training frames, and the interventions shown in 
TABLE 8.1

Active Learning Interventions: Core Training Components, Key Process Targets, and Individual Difference Considerations

\begin{tabular}{|c|c|c|c|c|}
\hline \multirow[b]{2}{*}{ Intervention } & \multirow[b]{2}{*}{ Studies } & \multicolumn{3}{|c|}{ Core Training Components } \\
\hline & & Instruction & Motivational Induction & Emotion Control \\
\hline $\begin{array}{l}\text { Exploratory } \\
\text { and } \\
\text { discovery } \\
\text { learning }\end{array}$ & $\begin{array}{l}\text { Frese et al. (1988) } \\
\text { Kamouri, Kamouri, and } \\
\text { Smith (1986) } \\
\text { McDaniel and Schlager } \\
(1990)\end{array}$ & $\begin{array}{l}\text { Exploratory learning: } \\
\text { - Limited guidance and } \\
\text { structure } \\
\text { - Exploration and discovery } \\
\text { inductive learning process }\end{array}$ & & \\
\hline $\begin{array}{l}\text { Guided } \\
\text { exploration }\end{array}$ & $\begin{array}{l}\text { Bell and Kozlowski (2002) } \\
\text { Debowski, Wood, and } \\
\text { Bandura (2001) } \\
\text { Wood, Kakebeeke, } \\
\text { Debowski, and Frese (2000) }\end{array}$ & $\begin{array}{l}\text { Exploratory learning: } \\
\text { - Limited guidance and } \\
\text { structure } \\
\text { - Exploration and discovery } \\
\text { - Inductive learning process } \\
\end{array}$ & $\begin{array}{l}\text { Error framing: } \\
\text { - Errors encouraged } \\
\text { - Errors framed as essential } \\
\text { for learning }\end{array}$ & $\begin{array}{l}\text { Emotion control statements: } \\
\text { - Statements designed to } \\
\text { reduce anxiety and } \\
\text { frustration } \\
\text { - Promote personal control }\end{array}$ \\
\hline $\begin{array}{l}\text { Error } \\
\text { training } \\
\text { and } \\
\text { enactive } \\
\text { exploration }\end{array}$ & $\begin{array}{l}\text { Frese et al. (1991) } \\
\text { Gully, Payne, Kiechel, and } \\
\text { Whiteman (2002) } \\
\text { Heimbeck, Frese, Sonnentag, } \\
\text { and Keith (2003) } \\
\text { Keith and Frese (2005) }\end{array}$ & $\begin{array}{l}\text { Guided exploration: } \\
\text { - Guidance on educational } \\
\text { decisions } \\
\text { - Systematic and preplanned } \\
\text { exploration }\end{array}$ & $\begin{array}{l}\text { Practice framing: } \\
\text { - Practice framed as } \\
\text { opportunity for learning } \\
\text { - Progressive achievement } \\
\text { to build self-efficacy }\end{array}$ & $\begin{array}{l}\text { Guided practice: } \\
\text { - Guided enactments of } \\
\text { practice strengthen } \\
\text { satisfaction with progress }\end{array}$ \\
\hline $\begin{array}{l}\text { Mastery } \\
\text { training }\end{array}$ & $\begin{array}{l}\text { Chillarege, Nordstrom, and } \\
\text { Williams (2003) } \\
\text { Kozlowski, Gully et al. (2001) } \\
\text { Kozlowski and Bell (2006) } \\
\text { Martocchio (1994) } \\
\text { Stevens and Gist (1997) } \\
\text { Tabernero and Wood (1999) }\end{array}$ & $\begin{array}{l}\text { Exploratory learning: } \\
\text { - Minimal to moderate } \\
\text { guidance } \\
\text { - Exploration and } \\
\text { experimentation } \\
\text { encouraged } \\
\text { - Active practice emphasized }\end{array}$ & $\begin{array}{l}\text { Mastery goals and framing: } \\
\text { - Mastery goals } \\
\text { - Errors framed as essential } \\
\text { for learning. } \\
\text { - Task ability framed as } \\
\text { acquirable skill }\end{array}$ & $\begin{array}{l}\text { Self-evaluative guidance: } \\
\text { - Training framed as learning } \\
\text { opportunity to reduce } \\
\text { performance anxiety } \\
\text { - Emphasis on self- } \\
\text { management and personal } \\
\text { control }\end{array}$ \\
\hline
\end{tabular}




\section{TABLE 8.1 (continued)}

Active Learning Interventions: Core Training Components, Key Process Targets, and Individual Difference Considerations

\begin{tabular}{|c|c|c|c|}
\hline & \multicolumn{3}{|c|}{ Core Training Components } \\
\hline & Instruction & Motivational Induction & Emotion Control \\
\hline Individual difference considerations & $\begin{array}{l}\text { - Cognitive ability } \\
\text { - Openness to experience }\end{array}$ & $\begin{array}{l}\text { - Trait goal orientation } \\
\text { - Conscientiousness }\end{array}$ & $\begin{array}{l}\text { - Cognitive ability } \\
\text { - Trait anxiety }\end{array}$ \\
\hline Key process targets & $\begin{array}{l}\text { - Cognition } \\
\text { - Metacognition } \\
\text { - Controlled and effortful } \\
\text { processing } \\
\text { - Mental models }\end{array}$ & $\begin{array}{l}\text { - Motivation } \\
\text { - State goal orientation } \\
\text { - Intrinsic motivation } \\
\text { - Self-efficacy } \\
\text { - Effort and persistence }\end{array}$ & $\begin{array}{l}\text { - Emotion } \\
\text { - Emotion regulation } \\
\text { - Satisfaction or negative } \\
\text { affect } \\
\text { - Anxiety } \\
\text { - Attributions }\end{array}$ \\
\hline Key training outcomes & \multicolumn{3}{|c|}{$\begin{array}{l}\text { Proximal outcomes: } \\
\text { - Strategic knowledge } \\
\text { - Strategic performance }\end{array}$} \\
\hline
\end{tabular}

Source: Bell, B. S., \& Kozlowski, S. W. J. (2008). Active learning: Effects of core training design elements on self-regulatory processes, learning, and adaptability. Journal of Applied Psychology, 93, 296-316. Published by the American Psychological Association. Adapted with permission. 
Table 8.1 evidence use of both strategies. Mastery training, for example, uses mastery goals that encourage trainees to focus their effort on developing their task competence rather than performing well (Kozlowski, Gully, et al., 2001). In contrast, error training incorporates instructions that encourage trainees to make errors and frame errors as instrumental for learning (Frese et al., 1991). These instructions, like the mastery goals, are designed to induce a mastery orientation and drive important motivational processes, such as intrinsic motivation and self-efficacy. Finally, because giving learners control over their instruction can increase stress and anxiety (Kanfer \& Heggestad, 1999; Keith \& Frese, 2005), many active learning interventions also incorporate a training design element aimed at helping trainees to regulate their emotions. Although a common element of active learning interventions, the specific emotion control strategies that have been employed are quite varied, including emotion control statements and different forms of guidance.

In Figure 8.2, we present an integrated conceptual model of active learning. Our goal in the following sections is to provide a more detailed examination of each of the three training components highlighted in the model and to highlight the relatively distinct self-regulatory pathways that each is designed to influence. In addition, we consider potential ATIs, where the effects of the training design components vary across trainees with different personal characteristics.

\begin{tabular}{|c|c|c|}
\hline Training Components & $\underline{\text { Self-Regulatory }}$ & Training Outcomes \\
\hline Nature of Instruction & Cognition & \\
\hline $\begin{array}{l}\text { - Exploration } \\
\text { - Experimentation } \\
\text { - Inductive learning } \\
\end{array}$ & $\begin{array}{l}\text { - Metacognition } \\
\text { - Effortful processing } \\
\text { - Mental models } \\
\end{array}$ & $\begin{array}{l}\text { Proximal Outcomes } \\
\text { Learning: } \\
\text { - Strategic knowledge }\end{array}$ \\
\hline \multirow{3}{*}{$\begin{array}{l}\begin{array}{c}\text { Motivational } \\
\text { Induction }\end{array} \\
\text { - Mastery goals } \\
\text { - Mastery training } \\
\text { frame } \\
\text { - Goal sequencing } \\
\end{array}$} & Motivation & $\begin{array}{l}\text { Performance: } \\
\text { - Strategic performance }\end{array}$ \\
\hline & $\begin{array}{l}\text { - Goal orientation } \\
\text { - Intrinsic motivation } \\
\text { - Self-efficacy }\end{array}$ & \\
\hline & & Distal Outcomes \\
\hline $\begin{array}{l}\text { Emotion Control } \\
\text { - Emotion-control } \\
\text { training } \\
\text { - Error-management } \\
\text { instructions } \\
\text { - Attributional } \\
\text { retraining }\end{array}$ & $\begin{array}{l}\quad \text { Emotion } \\
\text { - Anxiety } \\
\text { - Emotion regulation } \\
\text { - Performance } \\
\text { attributions }\end{array}$ & - Adaptive performance \\
\hline \multicolumn{2}{|c|}{ Individual Differences } & \\
\hline $\begin{array}{l}\text { - Cognitive abilit } \\
\text { - Openness to ex } \\
\text { - Trait goal orier }\end{array}$ & $\begin{array}{l}\text { - Conscientiousness } \\
\text { - Trait anxiety }\end{array}$ & \\
\hline
\end{tabular}

\section{FIGURE 8.2}

Integrated conceptual model of active learning. 


\section{Instruction}

A fundamental distinction between active and passive approaches to learning concerns the nature of instruction. In the active learning approach, the dominant pedagogical approach is exploratory or discovery learning, which refers to the acquisition of new information through activities initiated and controlled by the learner (Kamouri, Kamouri, \& Smith, 1986). Exploratory learning methods facilitate an inductive learning process in which individuals must explore and experiment with the task to infer and learn the rules, principles, and strategies for effective performance (Kamouri et al., 1986; Pearn \& Downs, 1989; Smith et al., 1997). Exploration can be encouraged by creating an open (unstructured) learning environment and/or by explicitly encouraging trainees to engage in exploratory behaviors. In contrast, more traditional, passive approaches to learning are characterized by a much more deductive instructional approach that explicitly instructs individuals on the complete task and its concepts, rules, and strategies. This type of learning is often referred to as proceduralized or expository instruction, because it provides trainees with detailed, step-by-step instructions and all the commands necessary for task performance (e.g., Dormann \& Frese, 1994; Frese et al., 1988, 1991; Nordstrom, Wendland, \& Williams, 1998).

It is important to recognize that pure exploratory or discovery learning and expository methods represent two ends of a continuum representing varying degrees of structure and guidance. Although pure exploratory learning remains a common active learning approach, it has also been criticized in recent years. Mayer (2004), for example, argued that instructional researchers have made the mistake of equating active teaching methods (e.g., hands-on activities and group discussions) with active learning. He suggested that the key to active learning is not learners' behavioral activity per se but, rather, their cognitive activity (e.g., selecting, organizing, and integrating knowledge). Moreover, he argued that on this latter criterion, pure exploratory methods often fall short. For instance, in pure exploratory learning, students may fail to come into contact with to-be-learned principles and, therefore, have nothing to integrate into their knowledge base. Mayer supported his position by reviewing research over the past 3 decades that has consistently shown that guided exploration leads to greater learning and transfer than pure exploration (see also Smith et al., 1997). Research on the topic of learner control has reached a similar conclusion, arguing that learners need guidance to help them make effective use of the control they are given (e.g., DeRouin et al., 2004; Reeves, 1993). The key point is that an appropriate mixture of exploration and guidance can balance the need for learners to be active during learning while also ensuring they make appropriate learning choices. Growing attention is being 
focused on incorporating guidance into active learning strategies (e.g., Bell \& Kozlowski, 2002), although more research is needed on how much and what kind of guidance to provide in different learning contexts.

Nonetheless, when exploratory methods are appropriately designed, they can serve as a useful means of engaging trainees' cognitive selfregulatory processes. Below, we discuss the effects of exploratory learning on three important cognitive learning processes: metacognition, effortful processing, and mental models.

\section{Metacognition}

Metacognition involves exerting control over self-monitoring and selfregulatory processes, and includes planning, monitoring, and revising goal-appropriate behavior (Brown, Bransford, Ferrara, \& Campione, 1983). Researchers have suggested that metacognition is critical for enabling learners to successfully orchestrate their own learning (Bransford, Brown, \& Cocking, 1999; Keith \& Frese, 2005). Cannon-Bowers et al. (1998), for example, argued that metacognition "assists learners in becoming active in their education instead of being passive recipients of instruction" (p. 296). In addition, metacognitive skills enable learners to recognize changes in task demands, devise new solutions, and evaluate the effectiveness of the implemented solution, all of which are critical elements of adaptability (Ford, Smith, Weissbein, Gully, \& Salas, 1998; Ivancic \& Hesketh, 2000).

One of the keys to building metacognitive skills is giving individuals an opportunity to engage in self-directed learning (Holyoak, 1991; Sweller, Mawer, \& Ward, 1983). The learner control inherent in exploratory learning prompts individuals to engage in planning, test their hypotheses, monitor their learning progress, and develop and revise learning strategies (Frese et al., 1988). Proceduralized instruction does not offer the opportunity to engage in metacognitive activities because individuals are provided with the correct task solution and exploration is restricted (Keith \& Frese, 2005). Further, Salomon and Globerson (1987) argued that when there is a perception that a particular authority "knows best," individuals will often forgo any mindful examination of information.

A recent study by Keith and Frese (2005) examined metacognition as an important cognitive self-regulatory process in error management training. Specifically, the authors argued that errors stimulate metacognitive activities by prompting individuals to diagnose their mistakes, devise and implement solutions, and monitor their effectiveness. Keith and Frese found that error management stimulated more metacognitive activity than error-avoidant training. Further, the authors found that this increase in metacognitive activity partially accounted for the positive relationship between error management training and adaptive transfer. A recent study 
by Bell and Kozlowski (2008) also provides evidence for the importance of metacognition in active learning. In this study, we hypothesized that guided exploration would stimulate greater metacognitive activity than more structured, proceduralized instruction. Our findings provided support for this hypothesis and also revealed that metacognitive activity positively predicted not only trainees' self-evaluation activity but also their intrinsic motivation and self-efficacy.

\section{Effortful Processing}

Exploratory learning may also increase the amount of cognitive effort that individuals devote to learning a task. In part, this may be due to the fact that exploratory learning increases the number of errors that occur during learning (Ivancic \& Hesketh, 1995). Not only do errors serve a surprise function that attracts individuals' attention, but also cognitive resources are required to diagnoses and recover from errors (Schönpflug, 1985). Exploratory learning may also require greater cognitive attention than proceduralized instruction because more effort is required to solve problems (Ivancic \& Hesketh, 1995). Tuovinen and Sweller (1999), for instance, compared the mental effort involved in using exploration or worked-examples practice to learn a database program. They found that exploratory learning required significantly higher levels of mental effort than worked-examples practice, especially for individuals with no previous domain familiarity. This increase in cognitive effort may be important because extending the length of time a skill is practiced using more effortful, controlled processing has been shown to foster schema extraction and the learning of principles (Sweller, 1988) and prevent the premature automatization of a skill (Frese \& Altmann, 1989).

\section{Mental Models}

Finally, exploratory learning may influence the coherence and breadth of trainees' knowledge structures. Because individuals must develop a solution to the task on their own, the knowledge they acquire through exploratory learning becomes better integrated into their existing knowledge (Egan \& Greeno, 1973; Frese et al., 1988). Individuals begin with a rudimentary conceptualization of the system, which guides their initial exploration. The more it is possible to integrate new information into these already existing conceptualizations, the better they are able to learn (Frese et al., 1988; Volpert, 1987). The knowledge is also more flexible because the effortful processing that occurs during exploratory learning leads to acquisition of knowledge at a higher level of regulation (Frese \& Zapf, 1994; Salomon \& Perkins, 1989). Proceduralized instruction, on the 
other hand, is often based on a very concrete representation of problemsolving actions, which may encourage individuals to represent the problem domain at an inappropriate level of abstraction (Carlson, Lundy, \& Schneider, 1992; Simons \& De Jong, 1992).

Exploratory learning also allows individuals to make errors, and, therefore, individuals learn not only from performing the task correctly but also from making mistakes (Ivancic \& Hesketh, 1995; Singer \& Pease, 1976). Making mistakes leads to the development of a better operative mental model of the task, because as individuals explore the task and make errors, they are able to incorporate potential pitfalls and error-prone areas into their mental model (Frese, 1995; Kozlowski, Gully, et al., 2001). In addition, exploration exposes individuals to a wider range of task material. Although some of this material may not be applicable to the current problem, it may prove useful when individuals are required to transfer their knowledge and skills and solve a novel problem (Kozlowski, Gully, et al.).

\section{ATIs}

Although the evidence reviewed above links exploratory learning to several important cognitive self-regulatory processes, research also suggests that a number of individual difference variables may moderate these effects. Snow (1986), for example, highlighted research that suggests that students with lower levels of ability benefit from tightly structured lessons, whereas students with higher levels of ability perform better in less structured, error-filled environments that provide room for independent learning. Similarly, Gully et al. (2002) found that high-ability trainees performed better under "make errors" instructions, whereas low-ability trainees performed better under "avoid errors" instructions. Bell and Kozlowski (2008) also found that high-ability trainees displayed higher levels of metacognitive activity when given guided exploratory learning compared to proceduralized instruction. It has been argued that low-ability trainees do not possess the cognitive resources necessary to make effective use of exploratory learning and errors (Gully et al., 2002). Further, as noted above, research has shown that exploratory learning increases trainees' workload (e.g., Schönpflug, 1985; Tuovinen \& Sweller, 1999), which may make it difficult for trainees with limited cognitive resources to devote adequate attention to both learning and self-regulatory activities.

Openness to experience may also moderate the impact of exploratory learning on learners' cognitive activity. Gully et al. (2002), for example, found that openness to experience moderated the impact of error training on several important training outcomes. Individuals high in openness to experience are more curious, imaginative, and broad-minded (Barrick \& 
Mount, 1991). They also may be more willing to engage in new approaches to learning, which may explain why openness to experience tends to have a positive impact on training proficiency (Barrick \& Mount, 1991). Consistent with past research, Gully et al. (2002) found that openness to experience was positively related to trainees' self-efficacy, knowledge, and performance. In addition, Gully et al. found that the positive relationship between openness to experience and training outcomes was particularly strong when training encouraged errors, but that these relationships disappeared when errors were discouraged. Gully et al. suggested that these results may be due to the facts that (a) error training encourages exploration and (b) trainees higher in openness are more likely to engage in exploratory behaviors. In other words, it appears that there is a particularly good fit between individuals high in openness to experience and more active, exploratory approaches to instruction. Proceduralized instruction, however, restricts exploration for trainees high in openness, thereby nullifying the positive effects of openness on training outcomes.

\section{Motivational Induction}

In recent years, the achievement goal literature has blended traditional conceptualizations of mastery and performance goals with classic achievement motivation theories, which differentiate between activities that are oriented toward the attainment of success (approach) and those that are oriented toward the avoidance of failure (e.g., Elliot \& Church, 1997; Harackiewicz, Barron, Pintrich, Elliot, \& Thrash, 2002). The result is three distinct motivational orientations: a mastery goal that emphasizes the development of competence and task mastery, a performance-prove goal that focuses on the attainment of favorable judgments of competence, and a performance-avoid goal that stresses avoiding perceptions of failure and incompetence (Elliot \& Church).

A second core element of many active learning interventions involves efforts to shape trainees' motivational orientation, or the achievement goals that trainees adopt with regard to the training task. Research has demonstrated that a variety of situational factors and inductions can be used to manipulate the achievement goals that individuals adopt (Archer, 1994; Boyle \& Klimoski, 1995; Tabernero \& Wood, 1999). In their ALS framework, Kozlowski, Toney, et al. (2001) divided these situational factors into two categories: instructional goals and general training frames.

Instructional goals are the explicit directions provided to trainees. These instructions suggest the behaviors and actions that trainees should engage in during training and, accordingly, identify the goals trainees should strive to achieve. Although training programs have traditionally been characterized by the assignment of performance goals, there is growing recognition that performance goals are often detrimental for knowledge 
and skill acquisition because they prompt a performance orientation and shift attention away from learning activities (Kanfer \& Ackerman, 1989; Locke, 2000; Seijts, Latham, Tasa, \& Latham, 2004). One solution is to provide individuals with mastery goals, which induce a mastery orientation and focus individuals' attention on discovering strategies and deeper comprehension of a task domain rather than on performing well (Kozlowski \& Bell, 2006; Locke \& Latham, 2002).

The second set of situational factors is general training frames. A mastery orientation can be induced by training instructions that do not focus explicitly on goals. Training settings that emphasize long-term outcomes and effort can induce a mastery orientation. Meece (1994), for example, suggested that training that emphasizes self-improvement and the usefulness of information provided in training will encourage the adoption of a mastery orientation. A mastery orientation can also be induced by instructions that stress self-referenced improvement and the malleability of ability, as opposed to the demonstration of fixed ability (Kozlowski \& Bell, 2006; Wood \& Bandura, 1989). Moreover, several studies indicate that a powerful means of inducing different motivational orientations involves the framing of errors (e.g., Bell \& Kozlowski, 2008; Frese et al., 1991; Kozlowski, Gully, et al., 2001; Martocchio, 1994). Learners are likely to adopt a mastery orientation when errors are framed as a normal and valuable part of the learning process and performance evaluation is deemphasized (Church, Elliot, \& Gable, 2001; Debowski et al., 2001; Kozlowski, Gully, et al., 2001; Martocchio, 1994). Thus, active learning strategies frequently incorporate task instructions that encourage learners to make errors and to view mistakes as instrumental for learning and self-improvement. In contrast, more traditional approaches to training, which subscribe to the belief that errors are negative occurrences that will detract from learning, encourage trainees to avoid making mistakes, an approach that is likely to induce a performance-avoid orientation (Church et al., 2001; Gully et al., 2002; Ivancic \& Hesketh, 1995).

Brown and Ford (2002) proposed that learners who adopt a mastery orientation are likely to be more active learners than those who adopt either a performance-prove or performance-avoid orientation. At the root of this argument is the differential effects of these orientations on how individuals approach, interpret, and respond to achievement activities. Indeed, a growing body of research has demonstrated a relationship between individuals' motivational orientation and their self-regulatory processes (see Payne, Youngcourt, \& Beaubien, 2007, for a review). Below, we discuss the effects of trainees' motivational orientation on their intrinsic motivation and self-efficacy, and also examine the potential role of motivational orientation as a prerequisite for other cognitive and emotional self-regulatory processes. 


\section{Intrinsic Motivation}

One key difference across the three orientations involves their effects on trainees' intrinsic motivation. A mastery orientation promotes challenging appraisals, encourages task absorption, and supports self-determination and feelings of autonomy, all factors presumed to facilitate intrinsic interest and enjoyment (Dweck, 1986). Performance orientations, on the other hand, produce evaluative pressures and elicit anxiety, processes considered antithetical to intrinsic motivation (McGregor \& Elliot, 2002). A meta-analysis by Rawsthorne and Elliot (1999) provided support for these different patterns and revealed that mastery orientation stimulates higher levels of intrinsic motivation than a performance orientation. Research that has further partitioned performance orientation into independent approach and avoidance motivational orientations suggests that only a performance orientation grounded in the avoidance of failure undermines intrinsic motivation (e.g., Elliot \& Harackiewicz, 1996). The effect of the performance-approach orientation on intrinsic motivation tends to be equivocal (e.g., Church et al., 2001; Elliot \& Church, 1997), which may be explained by the fact that approach orientation is undergirded by both a need for achievement and a fear of failure (Harackiewicz et al., 2002). From these findings, we can conclude that trainees who adopt a mastery orientation should exhibit higher levels of intrinsic motivation, which will in turn lead to greater engagement and effort during learning.

\section{Self-Efficacy}

Another difference between the three orientations concerns their effect on trainees' self-efficacy. Research has shown that high levels of mastery orientation tend to buffer individuals from the negative effects of failure, thereby helping to increase or maintain self-efficacy (e.g., Button, Mathieu, \& Zajac, 1996; Payne et al., 2007; Phillips \& Gully, 1997). In contrast, the evaluative pressures associated with performance orientation tend to lead to anxiety, which undermines self-efficacy and leads to a greater propensity to withdraw from tasks (especially in the face of failure). Colquitt and Simmering (1998), for example, demonstrated that mastery orientation not only leads to higher levels of motivation to learn than performance orientation but also buffers individuals from becoming demotivated in the face of performance difficulties. These findings have led researchers to conclude that trainees with a mastery orientation are likely to be more active, persistent learners (Brown \& Ford, 2002; Heimbeck et al., 2003). This may be particularly important in self-directed learning contexts (e.g., technology-based training, or on-the-job training $[\mathrm{OJT}])$, because trainees must self-diagnose and solve any obstacles they encounter during learning. 


\section{Supporting Cognitive and Emotional Processes}

In addition to influencing intrinsic motivation and self-efficacy, trainees' motivational orientation may also serve as a prerequisite for specific cognitive and emotional self-regulatory processes. Ford et al. (1998), for example, argued that a mastery orientation facilitates the use of deep processing strategies that require cognitive effort but facilitate understanding, whereas a performance orientation is related to more short-term and surface-level processing. Consistent with this rationale, Ford et al. showed that a mastery orientation led to higher levels of metacognitive activity than a performance orientation. Prior research has also demonstrated a significant relationship between individuals' motivational orientation and affective states (Elliot \& McGregor, 2001; McGregor \& Elliot, 2002). For example, a performance-avoid orientation tends to be associated with higher levels of state anxiety. These findings suggest that a mastery orientation may represent a critical condition for supporting the cognitive and emotional processes of active learning. Indeed, a recent study by Bell and Kozlowski (2008) provides evidence that the motivational pathway of active learning is intertwined with both the cognitive and emotion pathways.

\section{ATIS}

The goals that individuals adopt during training are determined by both situational factors and dispositional influences (Brett \& VandeWalle, 1999; Button et al., 1996; Chen et al., 2000). That is, individuals possess trait goal orientations that predispose them to adopt a mastery or a performance orientation in learning situations characterized by weak situational cues. Thus, it is possible that these two sources may interact to influence trainee orientation in a particular context. In particular, situational manipulations may be used to compensate for or balance a person's dispositional orientation (Bouffard, Boisvert, Vezeau, \& Larouche, 1995; Button et al.; Dweck \& Leggett, 1988; Newman, 1998). As Harackiewicz and Elliot (1993) noted, when an individual is characteristically oriented toward mastery (or performance), the external instantiation of such an orientation is likely to have little effect. Thus, mastery frames or goals will likely be a more powerful inducement of mastery orientation among trainees with low trait levels of mastery orientation.

Research by Gully et al. (2002) also suggests that conscientiousness may moderate the effect of specific goal frame manipulations. Specifically, Gully et al. found that individuals high in conscientiousness had higher levels of self-efficacy when they were encouraged to avoid errors, whereas individuals low in conscientiousness had higher levels of self-efficacy when encouraged to make errors. This finding is consistent with the fact that individuals high in conscientiousness tend to be careful, thorough, 
responsible, organized, achievement oriented, and hardworking (Barrick \& Mount, 1991; Martocchio \& Judge, 1997). In fact, one of the dimensions of conscientiousness is cautiousness (Costa \& McCrae, 1992; Hogan \& Ones, 1997), which has been measured by the extent to which individuals avoid mistakes (Goldberg, 1999). Thus, Gully et al. (2002) suggested that goal frames that are based on error encouragement may have negative effects for individuals high in conscientiousness because making mistakes is inconsistent with their natural disposition. Similarly, Bell and Kozlowski (2008) found that individuals who were high on performance-avoid orientation responded better to an error-avoidant condition (i.e., they exhibited less state avoidance and less anxiety) compared to a make-errors condition. Again, the result demonstrated that in some instances, it is better to design training to fit an individual's characteristic disposition than to try to change it.

\section{Emotion Control}

Although cognitive and motivational processes have garnered the greatest attention in active learning research, a number of researchers have argued that it is also important to consider the important role of emotion control in self-regulated learning. Simons and De Jong (1992) noted that "becoming an active learner is a difficult and stressful process" (p. 342). In a typical passive training program, trainees are provided with the information (e.g., rules, strategies) necessary for effective performance, which attenuates the standard learning curve. However, active learning approaches focus on improving performance after (as opposed to during) training (Keith \& Frese, 2005). In fact, many active learning approaches emphasize the positive function of errors, poor performance, and other challenges in learning. In addition, an instructor is often not present to help guide trainees through these challenges or to provide encouragement. Although the relatively unstructured environment of active learning and the challenges it presents may yield cognitive benefits, the risk is that it may also produce greater levels of frustration, stress, and anxiety. If not controlled, these negative reactions can not only be demotivating but also divert attentional resources away from on-task activities (Wood, Kakebeeke, Debowski, \& Frese, 2000).

Kanfer, Ackerman, and Heggestad (1996) defined emotion control as "the use of self-regulatory processes to keep performance anxiety and other negative emotional reactions (e.g., worry) at bay during task engagement ${ }^{\prime \prime}$ (p. 186). Emotion control may be particularly important during learning. As Kanfer and Heggestad (1999) noted, "Learners with poor emotioncontrol skills, in essence, compound the difficulty of learning a new task by being distracted by worry and anxiety" (p. 297). Negative emotions may be particularly damaging in the early stages of training, when cognitive 
demands are high (Kanfer \& Ackerman, 1989; Kanfer, Ackerman, Murtha, Dugdale, \& Nelson, 1994).

Over the years, many different techniques have been developed with the aim of helping individuals control their emotions in learning and performance contexts. These techniques include cue-controlled relaxation (Barrios, 1978; Benson, 1975), cognitive modification (e.g., Horan, Hackett, Buchanan, Stone, \& Demchik-Stone, 1977), and guided mental imagery (e.g., Carter \& Kelly, 1997; Sapp, 1994). Although these interventions can have a significant influence on individuals' affect and performance, one limitation of many of these programs is that they tend to require a considerable amount of training time. A typical intervention, for example, may involve five or six 2-hour instructional sessions (Rose \& Veiga, 1984). These sessions often focus on outlining the physiological and psychological mechanisms of stress, teaching individuals how to identify anxiety or stress cues, and instructing and practicing the particular emotion control skills. In many real-world training environments, this type of time commitment is just not feasible.

As a result, a number of researchers have explored whether it is possible to design emotion control techniques that are less resource intensive yet equally efficacious. A good example is the emotion control strategy developed by Kanfer and Ackerman $(1990,1996)$, which contains several key elements. First, trainees are told not to worry about their task performance early in training and not to be distracted by the errors that they make. Second, trainees are instructed to increase the frequency of positive thoughts and to reduce the frequency of negative emotions, such as worry or upset following errors (Kanfer \& Ackerman, 1996). Individuals receive instruction on the emotion control strategy prior to initial task performance, and between trials they are given emotion control reminders such as "Use the EMOTION CONTROL strategy while performing the task. That is, do not get upset or worry. Adopt a positive, 'CAN DO' attitude. This will improve your performance" (Kanfer \& Ackerman, 1990, p. 35). Kanfer and Ackerman (1990) found that trainees exposed to this emotion control strategy exhibited increased performance, reported fewer negative affective reactions, and made fewer attempts to monitor their performance score. In addition, the authors found that the beneficial effects of the emotion control strategy were most pronounced during the early stages of task performance. Once again, this is when task demands are the greatest and poor performance and errors are most likely. As Kanfer and Ackerman (1996) stated, "Emotion-control skills refer to self-regulatory patterns aimed at reducing the diversion of attentional resources to emotional concerns, and are most useful when attentional demands of the task are high" (p. 168).

The key elements of Kanfer and Ackerman's emotion control strategy are not unique and can be found singularly or in combination in a number of active learning strategies. For example, most studies on error training 
have integrated error management instructions or heuristics (e.g., "There is always a way to leave the error situation") into the strategy (Keith \& Frese, 2005, p. 681). These statements are presented repeatedly to learners during the course of training and are designed to reduce the negative emotions that often accompany errors and poor performance. Similarly, mastery training strategies often incorporate instructions designed to help reduce evaluative pressures surrounding performance. For example, the mastery training strategy evaluated by Kozlowski, Gully, et al. (2001) instructed trainees to use their scores as diagnostic feedback that could help them learn the task, rather than as indication of their ability. These instructions may promote more adaptive performance attributions (e.g., feelings of personal control), thereby reducing frustration and anxiety.

Despite this theoretical and empirical evidence, the importance of emotions in active learning has been debated over the years. For example, early research on error management training emphasized the importance of emotion control for reducing the frustration and anxiety that typically accompany errors (Frese et al., 1991). However, Frese (1995) noted difficulty in replicating the positive effects of emotion control and stated, "At this point in time, I have become more sceptical of the emotional hypothesis" (p. 119). However, more recent work has renewed interest in the emotion control component of active learning. In the following sections, we briefly discuss the potential effect of this emotion control component of the active learning approach on two affective self-regulatory processes: state anxiety and attributions.

\section{State Anxiety}

Keith and Frese (2005) found that error management training led to higher emotion control (i.e., greater use of emotional regulation strategies) than error-avoidant training and that emotion control positively affected adaptive transfer. Based on this finding, the authors concluded that emotional self-regulation plays an important role in active learning. Another study by Bell and Kozlowski (2008) examined the implications of including emotion control training as part of an active learning strategy. The emotion control training lowered trainees' state anxiety, which in turn led to higher levels of self-efficacy and adaptive performance. These emerging findings suggest that emotion control is an important self-regulatory element of active learning due not only to its direct effects on learning and performance but also to its role in supporting other key self-regulation processes.

\section{Attributions}

One process variable that has yet to be examined in active learning research but nonetheless may be important in emotion regulation 
concerns trainees' performance attributions. Prior research has revealed that negative emotions occur when an individual makes a cognitive appraisal that a substantial imbalance exists between perceived environmental demands and perceived response capability (McGrath, 1970). Attributions play an important role in an individual's perception of his or her response capability. In particular, individuals who perceive greater personal control over their current situation tend to experience lower levels of anxiety. This relates to the fact that individuals who perceive that they can respond to environmental demands tend to experience less anxiety. DuCette and Wolk (1973), for example, found that individuals with a more internal locus of control were more likely to believe they could meet situational demands and, therefore, experienced less anxiety than individuals with a more external locus of control.

A major risk in giving individuals control over their learning and encouraging them to make errors is that they will get trapped in an error state, feel helpless, and withdraw from the task. Recognizing this, the emotion control strategies highlighted above include components designed to help shape learners' attributions. For example, emotion control statements such as "There is always a way to leave the error situation" are aimed, in part, at countering feelings of helplessness and increasing individuals' perceptions of control. By instructing individuals to adopt a "can-do" attitude, Kanfer and Ackerman's (1990) emotion control intervention also influences individuals' attributions. Accordingly, future research should consider trainees' attributions, in particular their locus of control, as an important process involved in emotional regulation during active learning.

\section{ATIS}

It is important to highlight that Kanfer and Ackerman (1990) found that their emotion control strategy had positive effects for low-ability trainees but did not benefit high-ability trainees. They suggested that low-ability individuals benefited the most from the strategy because they were more likely to make errors, perform poorly, and, therefore, experience negative affect. In addition, a number of researchers (e.g., Kanfer \& Ackerman, 1990; Reason, 1990; Wood et al., 2000) have argued that emotions, such as stress and anxiety, increase cognitive load and divert attentional resources away from the task at hand. Whereas high-ability individuals may have ample cognitive resources to split between performing a task and monitoring their emotions, low-ability individuals have more limited cognitive resources. As a result, any diversion of their resources away from the task probably has a significant and negative impact on their performance. Overall, these findings suggest that cognitive ability may moderate the effects of emotion control strategies, such that their impact will be greater for low-ability individuals because of their increased susceptibility to 
negative emotions and the significant impact that any type of distraction will have on their performance.

A second important individual difference to consider is trait anxiety. Research has shown that individuals differ in terms of their natural, or trait, level of anxiety (e.g., Gaudry, Vagg, \& Spielberger, 1975; Spielberger, 1985). Whereas some individuals are relatively immune to anxiety and stress, other individuals are prone to such emotions. Put simply, some individuals are more likely than others to experience high levels of state anxiety. These differences in trait anxiety, therefore, may play an important role in determining the impact of an emotion control strategy. Individuals who are anxiety prone are more likely to react negatively to events, such as errors, and be distracted by the worry and anxiety that accompany them. In contrast, individuals who have relatively low levels of trait anxiety will be less likely to develop anxiety and, therefore, be distracted by their emotions. As a result, an emotion control strategy should be especially important for individuals high in trait anxiety, because of their enhanced susceptibility to state anxiety.

\section{Outcomes of the Active Learning Approach}

Although it is clear that the active learning approach has the potential to enhance trainees' knowledge and performance, it is also important to recognize that the effects of this approach are not uniform across all types of learning outcomes or at all periods of time. In particular, most active learning strategies are designed to improve outcomes after, as opposed to during, training. Error training, for example, often leads to lower levels of training performance because trainees experiment, make errors, and sometimes arrive at wrong solutions (Keith \& Frese, 2005). The benefits of error training typically do not emerge until one examines trainees' performance in the long run or the transfer of knowledge and skills to new problems (Bell \& Kozlowski, 2008; Hesketh, 1997). Similarly, mastery inductions often lead to lower levels of performance in the short term because trainees are focused on developing rather than demonstrating their competence. Again, it is often not until one examines trainees' transfer performance that the benefits of mastery training become evident. An important implication of these findings is that assessments of trainees skills during or immediately following training may not provide an accurate indication of the utility of active learning strategies. In the sections that follow, we further examine the implications of the active learning approach for different types of training outcomes by considering the distinction between basic and strategic outcomes and analogical and adaptive transfer. 


\section{Basic Versus Strategic Outcomes}

Several researchers have argued that the effectiveness of the active learning approach may depend on the complexity of the skills being trained. Clark and Voogel (1985), for example, argued that more basic, proceduralized skills lend themselves to training by errorless learning and more traditionally behavioristic techniques, whereas more cognitively based and complex skills that require conceptual knowledge or the development of a mental model and strategies are better suited to exploratory learning. Similarly, Heimbeck et al. (2003) predicted and found benefits for error training on difficult but not easy tasks. They suggested that performance in easy tasks does not benefit from error management training because easy tasks require only basic skills and typically involve few errors. Overall, active learning approaches are likely to yield little benefit over more traditional, proceduralized approaches when the goal is the development of basic declarative knowledge and skills (e.g., McDaniel \& Schlager, 1990). However, on more complex tasks where performance depends on the development of strategic competencies, the active learning approach is typically superior to traditional forms of instructions (Frese, 1995).

\section{Analogical Versus Adaptive Transfer}

The active learning approach may also be more effective for specific types of transfer. For example, numerous studies have shown that exploratory learning and proceduralized instruction produce similar levels of analogical or near transfer (e.g., Dormann \& Frese, 1994; McDaniel \& Schlager, 1990), which involves the application of trained skills to problems analogous to those encountered during training. However, exploratory learning has also been shown to be superior to proceduralized instruction for facilitating adaptive transfer (Bell \& Kozlowski, 2008; Frese et al., 1988; Kamouri et al., 1986), or the transfer of skills to novel problems. Similarly, Keith and Frese (2005) argued that error training should be particularly effective for promoting adaptive transfer because trainees learn to deal with unexpected problems. Indeed, they found that error management and error-avoidant training led to similar levels of analogical transfer, but error management training resulted in higher levels of adaptive transfer. Finally, Kozlowski, Gully, et al. (2001) found that mastery training enhanced trainees' adaptive performance through its positive effects on their knowledge coherence and self-efficacy. Although these findings emerged from research on specific active learning strategies, the overall body of evidence suggests that although the benefits of the active learning approach for analogical transfer are negligible, it leads to higher levels of adaptive transfer than more traditional instruction. 


\section{A Research Agenda}

As highlighted at the outset of this chapter, substantial changes in the nature of work and organizations have occurred in recent years (Salas \& Cannon-Bowers, 2001). These changes have forced organizations to rethink the nature of training as it has become clear that many of our traditional training tools and principles are not well suited for developing the adaptive competencies required for success in an increasing number of jobs. Moreover, training today is increasingly being delivered via technology-based methods and embedded in the work environment, placing greater demands on employees to manage their own learning. These and other trends have stimulated interest in the concept of active learning, not only because of its role in developing complex and adaptive skills but also because of its importance in the process of self-directed learning. A number of recent studies have been instrumental in demonstrating the utility of active learning strategies for enhancing trainee self-regulation, learning, and adaptability. Yet, a comprehensive theory of active learning remains elusive, and many important questions persist.

The goal of this chapter was to develop a comprehensive and integrative framework of active learning. In the preceding sections, we discussed the different elements of this framework, including the core training components that cut across different active learning interventions; the cognitive, motivational, and emotion self-regulatory pathways these components influence; the individual differences that moderate the effects of the training components; and the anticipated outcomes of the active learning approach. Although we believe this is an important first step toward developing a theory of active learning and learner-centered training design, we also recognize that much more work is needed. In this final section of the chapter, we use the framework to highlight several potentially fruitful areas of future research in the area of active learning.

\section{Core Training Components and Individual Differences}

As argued throughout this chapter, it is important that future research move beyond testing multifaceted active learning strategies to examining the effects of the core training components on self-regulatory processes and training outcomes. This is not to say that we should avoid intervention-based research, but it will be important to ensure that new interventions are conceptually linked to the core components so we understand their training design features and the process pathways through which these interventions operate. Through the elaboration of the components embedded in different active learning strategies, results across 
studies will be more readily compared and integrated, thereby facilitating the development of a theory of active learning.

Future research on active learning must also continue to adopt an aptitude-treatment perspective. A number of recent studies have provided valuable insight into the effects of individual differences on how learners interact with active learning interventions (e.g., Gully et al., 2002; Heimbeck et al., 2003), but to date the focus has been limited to cognitive ability and a small set of dispositional traits (e.g., conscientiousness). More research is needed to not only expand this focus to include previously unexamined individual differences, such as trait anxiety or self-regulatory focus, but also explore how these individual differences interact with specific training components to influence particular self-regulatory processes.

\section{Elaborating Process Pathways}

In this chapter, we have also argued for greater emphasis on understanding the processes that define active learning and the process pathways through which the different training components exert their effects on learning, performance, and adaptability. In this regard, it is important to note that some of these active learning mechanisms have received more attention than others. In the cognitive domain, for example, recent research has firmly established metacognition as an important selfregulatory process underlying active learning (e.g., Bell \& Kozlowski, 2008; Keith \& Frese, 2005; Schmidt \& Ford, 2003). However, other potentially important cognitive self-regulatory processes, such as effortful processing and mental models, have received very little attention. Similarly, significant research has demonstrated that intrinsic motivation and self-efficacy are important mediators of the effects of mastery inductions on learning and performance (e.g., Kozlowski, Toney, et al., 2001; Phillips \& Gully, 1997; Rawsthorne \& Elliot, 1999), but the effects of emotion control strategies on trainees' emotional regulation and emotion states have not been widely studied. Accordingly, it will be important to expand the scope of self-regulatory processes examined in future active learning research.

Relative to the cognitive and motivational components of active learning, the emotion component has received much less support over the years (Frese, 1995). Although a few recent studies have provided evidence that emotional regulation is important in the active learning approach (e.g., Bell \& Kozlowski, 2008; Keith \& Frese, 2005), we lack a solid understanding of how to effectively utilize emotion control strategies in training. For example, in situations where anxiety levels do not reach a level where they cause significant decrements in performance, encouraging trainees to focus on regulating their emotions may have little utility and in fact may be harmful due to decreased attentional resources and on-task focus. 
More research is needed to better identify those situations in which it is critical to incorporate an emotion control strategy into training. Different methods of implementing emotion control strategies should also be examined. For example, Heimbeck et al. (2003) argued that it may be most appropriate to implement emotion control interventions only after trainees have acquired a foundation of knowledge and skills, but Kanfer and Ackerman (1990) suggested that there may be utility in gradually phasing out these interventions over the course of training. It is important to determine whether one of these competing recommendations is more effective than the other.

\section{Unpacking Adaptation}

One of the themes underlying research on active learning is the prospect that it enables adaptive expertise (Smith et al., 1997), the ability to flexibly adjust one's learning when the task becomes more difficult, complex, and dynamic. One general finding is that adaptive learning often appears to slow or inhibit training performance, but the payoff appears when capabilities have to be applied to a changed task. Some active learning research has helped to identify self-regulatory constructs that underlie adaptive performance. For example, at the individual level, Kozlowski, Gully, et al. (2001) showed that knowledge structure coherence and self-efficacy were predictive of adaptive performance after declarative knowledge, training performance, and cognitive ability had been controlled. They reasoned that knowledge coherence allowed trainees to extrapolate what they had learned to a changed task situation, and self-efficacy enabled trainees to persist in spite of the difficulties they encountered when the task changed. However, as a general rule, the process of adaptation has not yet been a central focus in most active learning research. We think the process framework we have outlined in this chapter can be extended to better unpack the underpinnings of adaptive performance.

Work by LePine, Colquitt, and Erez (2000) has shown that conscientiousness, which is generally regarded as a positive contributor to task performance, inhibits individual adaptation when a task has changed. Similar to the findings by Gully et al. (2002), it appears that the dependability and persistence aspects of conscientiousness prevent an individual from exploring alternative actions when what had been successful no longer works. In addition, more recent work by LePine (2005) has shown that when teams have to adapt to an unexpected change, those teams that were more performance oriented failed to adapt well, whereas those teams that were more mastery oriented were better able to detect the need to change and to discover an appropriate adaptive strategy. In this vein, 
recent research by Chen, Wallace, and Thomas (2005) modeled self-regulatory processes to link end-of-training outcomes and adaptive performance. Although neither of these studies was directly relevant to active learning interventions, they suggest a promising extension to the paradigm that would begin to probe the process of adaptation that warrants further investigation.

\section{Conclusion}

More than a decade of research has shown that active learning interventions, such as error training, mastery training, and guided exploration, are useful tools for promoting learning, performance, and, in particular, adaptability (Smith et al., 1997). However, what is less well understood is how these interventions work-which training components are essential to their success, and what are the process mechanisms through which they operate? In addition, it remains unclear for whom these interventions are most effective. This chapter advances recent research on active learning (e.g., Keith \& Frese, 2005; Kozlowski \& Bell, 2006) by shifting the theoretical focus from one of intervention design (e.g., Kozlowski, Toney, et al., 2001) to one providing an integrative framework that identifies the core training components of active learning interventions, maps these components onto self-regulatory process pathways that drive important training outcomes, and highlights possible aptitude-treatment interactions that detail how different trainees may interact with specific components of active learning interventions. Ultimately, we hope that this effort will stimulate future theory development and empirical research aimed at better understanding active learning and advancing the science of learner-centered training design.

\section{References}

Archer, J. (1994). Achievement goals as a measure of motivation in university students. Contemporary Educational Psychology, 19, 430-446.

Barrick, M. R., \& Mount, M. K. (1991). The Big Five personality dimensions and job performance: A meta-analysis. Personnel Psychology, 44, 1-26.

Barrios, B. A. (1978). Cue controlled relaxation as a generalizable coping skill. Psychology, 15, 14-17. 
Bell, B. S., \& Kozlowski, S. W. J. (2002). Adaptive guidance: Enhancing selfregulation, knowledge, and performance in technology-based training. Personnel Psychology, 55, 267-306.

Bell, B. S., \& Kozlowski, S. W. J. (2008). Active learning: Effects of core training design elements on self-regulatory processes, learning, and adaptability. Journal of Applied Psychology, 93, 296-316.

Benson, H. (1975). The relaxation response. New York: Avon.

Bouffard, T., Boisvert, J., Vezeau, C., \& Larouche, C. (1995). The impact of goal orientation on self-regulation and performance among college students. British Journal of Educational Psychology, 65, 317-329.

Boyle, K., \& Klimoski, R. J. (1995, May). Toward an understanding of goal orientation in a training context. Paper presented at the 10 th Annual Conference of the Society for Industrial/Organizational Psychology, Orlando, FL.

Bransford, J. D., Brown, A. L., \& Cocking, R. R. (Eds.). (1999). How people learn: Brain, mind, experience, and school. Washington, DC: National Academy Press.

Brett, J. F., \& VandeWalle, D. (1999). Goal orientation and goal content as predictors of performance in a training program. Journal of Applied Psychology, 84, 863-873.

Brown, A. L., Bransford, J. D. Ferrara, R. A., \& Campione, J. C. (1983). Learning, remembering, and understanding. In J. H. Flavell \& E. M. Markman (Eds.), Handbook of child psychology (Vol. 3, pp. 77-166). New York: Wiley.

Brown, K. G. (2001). Using computers to deliver training: Which employees learn and why? Personnel Psychology, 54, 271-296.

Brown, K. G., \& Ford, J. K. (2002). Using computer technology in training: Building an infrastructure for active learning. In K. Kraiger (Ed.), Creating, implementing, and managing effective training and development (pp. 192-233). San Francisco: Jossey-Bass.

Button, S. B., Mathieu, J. E., \& Zajac, D. M. (1996). Goal orientation in organizational research: A conceptual and empirical foundation. Organizational Behavior and Human Decision Processes, 67, 26-48.

Cannon-Bowers, J. A., Rhodenizer, L., Salas, E., \& Bowers, C. A. (1998). A framework for understanding pre-practice conditions and their impact on learning. Personnel Psychology, 51, 291-320.

Carlson, R. A., Lundy, D. H., \& Schneider, W. (1992). Strategy guidance and memory aiding in learning a problem-solving skill. Human Factors, 34, 129-145.

Carter, J. E., \& Kelly, A. E. (1997). Using traditional and paradoxical imagery interventions with reactant intramural athletes. The Sports Psychologist, 11, 175-189.

Carver, C. S., \& Scheier, M. F. (1990). Origins and functions of positive and negative affect: A control-process view. Psychological Review, 97, 19-35.

Chen, G., Gully, S. M., Whiteman, J., \& Kilcullen, R. N. (2000). Examination of relationships among trait-like individual differences, state-like individual differences, and learning performance. Journal of Applied Psychology, 85, 835-847.

Chen, G., Thomas, B., \& Wallace, J. C. (2005). A multilevel examination of the relationships among training outcomes, mediating regulatory processes, and adaptive performance. Journal of Applied Psychology, 90, 827-841. 
Chillarege, K. A., Nordstrom, C. R., \& Williams, K. B. (2003). Learning from our mistakes: Error management training for mature learners. Journal of Business and Psychology, 17, 369-385.

Church, M. A., Elliot, A. J., \& Gable, S. L. (2001). Perceptions of classroom environment, achievement goals, and achievement outcomes. Journal of Educational Psychology, 93, 43-54.

Clark, R. E. (2001). Learning from media: Arguments, analysis, and evidence. Greenwich, CT: Information Age.

Clark, R. E., \& Voogel, A. (1985). Transfer of training principles for instructional design. Educational Communication and Technology Journal, 33, 113-123.

Colquitt, J. A., LePine, J. A., \& Noe, R. A. (2000). Toward an integrative theory of training motivation: A meta-analytic path analysis of twenty years of research. Journal of Applied Psychology, 85, 678-707.

Colquitt, J. A., \& Simmering, M. J. (1998). Conscientiousness, goal orientation, and motivation to learn during the learning process: A longitudinal study. Journal of Applied Psychology, 83, 654-665.

Costa, P. T., Jr., \& McCrae, R. R. (1992). Revised NEO Personality Inventory (NEO$P I-R)$ and NEO Five-Factor Inventory (NEO-FFI) professional manual. Odessa, FL: Psychological Assessment Resources.

Debowski, S., Wood, R. E., \& Bandura, A. (2001). Impact of guided exploration and enactive exploration on self-regulatory mechanisms and information acquisition through electronic search. Journal of Applied Psychology, 86, 1129-1141.

DeRouin, R. E., Fritzsche, B. A., \& Salas, E. (2004). Optimizing e-learning: Researchbased guidelines for learner-controlled training. Human Resource Management, $43,147-162$.

Dormann, T., \& Frese, M. (1994). Error training: Replication and the function of exploratory behavior. International Journal of Human-Computer Interaction, 6 , 365-372.

DuCette, J., \& Wolk, S. (1973). Cognitive and motivational correlates of generalized expectancies for control. Journal of Personality and Social Psychology, 26, 420-429.

Dweck, C. S. (1986). Mental processes affecting learning. American Psychologist, 41, 1040-1048.

Dweck, C. S., \& Leggett, E. L. (1988). A social-cognitive approach to motivation and personality. Psychological Review, 95, 256-273.

Egan, D. E., \& Greeno, J. G. (1973). Acquiring cognitive structure by discovery and rule learning. Journal of Educational Psychology, 64, 85-97.

Elliot, A. J., \& Church, M. A. (1997). A hierarchical model of approach and avoidance achievement motivation. Journal of Personality and Social Psychology, 72, 218-232.

Elliot, A. J., \& Harackiewicz, J. M. (1996). Approach and avoidance achievement goals and intrinsic motivation: A mediational analysis. Journal of Personality and Social Psychology, 70, 461-475.

Elliot, A. J., \& McGregor, H. (2001). A $2 \times 2$ achievement goal framework. Journal of Personality and Social Psychology, 80, 501-519.

Ford, J. K., Smith, E. M., Weissbein, D. A., Gully, S. M., \& Salas, E. (1998). Relationships of goal orientation, metacognitive activity, and practice strategies with learning outcomes and transfer. Journal of Applied Psychology, 83, 218-233. 
Frese, M. (1995). Error management in training: Conceptual and empirical results. In C. Zucchermaglio, S. Bagnara, \& S. U. Stuchy (Eds.), Organizational learning and technological change (pp. 112-124). New York: Springer-Verlag.

Frese, M., Albrecht, K., Altmann, A., Lang, J., Papstein, P. V., Peyerl, R., et al. (1988). The effects of an active development of the mental model in the training process: Experimental results in a word processing system. Behaviour and Information Technology, 7, 295-304.

Frese, M., \& Altmann, A. (1989). The treatment of errors in learning and training. In L. Bainbridge \& S. A. R. Quintanilla (Eds.), Developing skills with new technology (pp. 65-86). Chichester, UK: Wiley \& Sons.

Frese, M., Brodbeck, F., Heinbokel, T., Mooser, C., Schleiffenbaum, E., \& Thiemann, P. (1991). Errors in training computer skills: On the positive function of errors. Human-Computer Interaction, 6, 77-93.

Frese, M., \& Zapf, D. (1994). Action as the core of work psychology: A German approach. In H. C. Triandis, M. D. Dunnette, \& L. M. Hough (Eds.), Handbook of industrial and organizational psychology (2nd ed., Vol. 4, pp. 271-340). Palo Alto, CA: Consulting Psychologists.

Gaudry, E., Vagg, P., \& Spielberger, C. D. (1975). Validation of the state-trait distinction in anxiety research. Multivariate Behavioral Research, 10, 331-341.

Goldberg, L. R. (1999). A broad-bandwidth, public-domain, personality inventory measuring the lower-level facets of several five-factor models. In I. Mervielde, I. Deary, F. DeFruyt, \& F. Ostendorf (Eds.); Personality psychology in Europe (Vol. 7, pp. 7-28). Tilburg, The Netherlands: Tilburg University Press.

Gully, S. M., Payne, S. C., Kiechel, K. L., \& Whiteman, J. K. (2002). The impact of error training and individual differences on training outcomes: An attributetreatment interaction perspective. Journal of Applied Psychology, 87, 143-155.

Harackiewicz, J. M., Barron, K. E., Pintrich, P. R., Elliot, A. J., \& Thrash, T. M. (2002). Revision of achievement goal theory: Necessary and illuminating. Journal of Educational Psychology, 94(3), 638-645.

Harackiewicz, J. M., \& Elliot, A. J. (1993). Achievement goals and intrinsic motivation. Journal of Personality and Social Psychology, 65, 904-915.

Heimbeck, D., Frese, M., Sonnentag, S., \& Keith, N. (2003). Integrating errors into the training process: The function of error management instructions and the role of goal orientation. Personnel Psychology, 56, 333-361.

Hesketh, B. (1997). Dilemmas in training for transfer and retention. Applied Psychology: An International Review, 46, 317-339.

Hogan, J., \& Ones, D. S. (1997). Conscientiousness and integrity at work. In R. Hogan, J. Johnson, \& S. Briggs (Eds.), Handbook of personality psychology (pp. 849-870). San Diego, CA: Academic Press.

Holyoak, K. J. (1991). Symbolic connectionism: Toward third-generation theories of expertise. In K. A. Ericsson \& J. Smith (Eds.), Toward a general theory of expertise (pp. 301-336). Cambridge, UK: Cambridge University Press.

Horan, J. J., Hackett, G., Buchanan, J. D., Stone, G. I., \& Demchik-Stone, D. (1977). Coping with pain. A component analysis of stress inoculation. Cognitive Therapy and Research, 1, 211-221.

Iran-Nejad, A. (1990). Active and dynamic self-regulation of learning processes. Review of Educational Research, 60, 573-602. 
Ivancic, K., \& Hesketh, B. (1995). Making the best of errors during training. Training Research Journal, 1, 103-125.

Ivancic, K., \& Hesketh, B. (2000). Learning from error in a driving simulation: Effects on driving skill and self-confidence. Ergonomics, 43, 1966-1984.

Kamouri, A. L., Kamouri, J., \& Smith, K. H. (1986). Training by exploration: Facilitating the transfer of procedural knowledge through analogical reasoning. International Journal of Man-Machine Studies, 24, 171-192.

Kanfer, R., \& Ackerman, P. L. (1989). Motivation and cognitive abilities: An integrative/aptitude-treatment interaction approach to skill acquisition. Journal of Applied Psychology-Monograph, 74, 657-690.

Kanfer, R., \& Ackerman, P. L. (1990). Ability and metacognitive determinants of skill acquisition and transfer (Air Force Office of Scientific Research Final Report). Minneapolis, MN: Air Force Office of Scientific Research.

Kanfer, R., \& Ackerman, P. L. (1996). A self-regulatory skills perspective to reducing cognitive interference. In I. G. Sarason, G. R. Pierce, \& B. R. Sarason (Eds.), Cognitive interference: Theories, methods, and findings (pp. 153-171). Mahwah, NJ: Lawrence Erlbaum Associates.

Kanfer, R., Ackerman, P. L., \& Heggestad, E. D. (1996). Motivational skills and selfregulation for learning: A trait perspective. Learning and Individual Differences, 8, 185-209.

Kanfer, R., Ackerman, P. L., Murtha, T. C., Dugdale, B., \& Nelson, L. (1994). Goal setting, conditions of practice, and task performance: A resource allocation perspective. Journal of Applied Psychology, 79, 826-835.

Kanfer, R., \& Heggestad, E. D. (1999). Individual differences in motivation: Traits and self-regulatory skills. In P. L. Ackerman, P. C. Kyllonen, \& R. D. Roberts (Eds.), Learning and individual differences: Process, trait, and content determinants (pp. 293-309). Washington, DC: American Psychological Association.

Karoly, P. (1993). Mechanisms of self-regulation: A systems view. Annual Review of Psychology, 44, 23-52.

Keith, N., \& Frese, M. (2005). Self-regulation in error management training: Emotion control and metacognition as mediators of performance effects. Journal of Applied Psychology, 90, 677-691.

Kluger, A., \& DeNisi, A. (1996). The effects of feedback interventions on performance: A historical review, a meta-analysis, and a preliminary intervention theory. Psychological Bulletin, 119, 254-284.

Kolb, D. A. (1984). Experiential learning. Englewood Cliffs, NJ: Prentice Hall.

Kozlowski, S. W. J., \& Bell, B. S. (2006). Disentangling achievement orientation and goal setting: Effects on self-regulatory processes. Journal of Applied Psychology, $91,900-916$.

Kozlowski, S. W. J., Gully, S. M., Brown, K. G., Salas, E., Smith, E. M., \& Nason, E. R. (2001). Effects of training goals and goal orientation traits on multidimensional training outcomes and performance adaptability. Organizational Behavior and Human Decision Processes, 85, 1-31.

Kozlowski, S. W. J., Toney, R. J., Mullins, M. E., Weissbein, D. A., Brown, K. G., \& Bell, B. S. (2001). Developing adaptability: A theory for the design of integrated-embedded training systems. In E. Salas (Ed.), Human/technology interaction in complex systems (Vol. 10). Greenwich, CT: JAI. 
Kraiger, K., Ford, J. K., \& Salas, E. (1993). Application of cognitive, skill-based, and affective theories of learning outcomes to new methods of training evaluation. Journal of Applied Psychology, 78, 311-328.

LePine, J. A. (2005). Adaptation in teams in response to unforeseen change: Effects of goal difficulty and team composition in terms of cognitive ability and goal orientation. Journal of Applied Psychology, 90, 1153-1167.

LePine, J. A., Colquitt, J. A., \& Erez, A. (2000). Adaptability to changing tasks contexts: Effects of general cognitive ability, conscientiousness, and openness to experience. Personnel Psychology, 53, 563-593.

Locke, E. A. (2000). Motivation, cognition, and action: An analysis of studies of task goals and knowledge. Applied Psychology: An International Review, 49, 408-429.

Locke, E. A., \& Latham, G. P. (2002). Building a practically useful theory of goal setting and task motivation: A 35-year odyssey. American Psychologist, 57, 705-717.

Martocchio, J. J. (1994). Effects of conceptions of ability, and academic achievement. Journal of Applied Psychology, 79, 819-825.

Martocchio, J. J., \& Judge, T. A. (1997). Relationship between conscientiousness and learning in employee training: Mediating influences of self-deception and self-efficacy. Journal of Applied Psychology, 82, 764-773.

Mayer, R. E. (2004). Should there be a three-strikes rule against pure discovery learning? The case for guided methods of instruction. American Psychologist, $59,14-19$.

McDaniel, M. A., \& Schlager, M. S. (1990). Discovery learning and transfer of problem-solving skills. Cognition and Instruction, 7, 129-159.

McGrath, J. E. (1970). Social and psychological factors in stress. New York: Holt, Rinehart \& Winston.

McGregor, H., \& Elliot, A. J. (2002). Achievement goals as predictors of achievement related processes prior to task engagement. Journal of Educational Psychology, 94, 381-395.

Meece, J. (1994). The role of motivation in self-regulated learning. In D. H. Schunk \& B. J. Zimmerman (Eds.), Self-regulation of learning and performance (pp. 25-44). Hillsdale, NJ: Lawrence Erlbaum Associates.

Newman, R. S. (1998). Students' help seeking during problem solving: Influences of personal and contextual achievement goals. Journal of Educational Psychology, $90,644-658$.

Nordstrom, C. R., Wendland, D., \& Williams, K. B. (1998). "To err is human": An examination of the effectiveness of error management training. Journal of Business and Psychology, 12, 269-282.

Payne, S. C., Youngcourt, S. S., \& Beaubien, J. M. (2007). A meta-analytic examination of the goal orientation nomological net. Journal of Applied Psychology, 92, $128-150$.

Pearn, M., \& Downs, S. (1989). Adapting to new technology by developing skilled learners. Paper presented at the 4th West European Congress on the Psychology of Work and Organisation: Working With Change, Cambridge, UK.

Phillips, J. M., \& Gully, S. M. (1997). Role of goal orientation, ability, need for achievement, and locus of control in the self-efficacy and goal-setting process. Journal of Applied Psychology, 82, 792-802. 
Rawsthorne, L. J., \& Elliot, A. J. (1999). Achievement goals and intrinsic motivation: A meta-analytic review. Personality and Social Psychological Review, 3, 326-344.

Reason, J. (1990). Human error. New York: Cambridge University Press.

Reeves, T. C. (1993). Pseudoscience in computer-based instruction: The case of learner control research. Journal of Computer-Based Instruction, 20, 39-46.

Revans, R. W. (1982). The origins and growth of action learning. Bromley, UK: Chartwell-Bratt.

Rose, R. L., \& Veiga, J. F. (1984). Assessing the sustained effects of a stress management intervention on anxiety and locus of control. Academy of Management Journal, 27, 190-198.

Salas, E., \& Cannon-Bowers, J. A. (2001). The science of training: A decade of progress. Annual Review of Psychology, 52, 471-499.

Salomon, G., \& Globerson, T. (1987). Skill is not enough: The role of mindfulness in learning and transfer. International Journal of Research in Education, 11, 623-638.

Salomon, G., \& Perkins, D. N. (1989). Rocky roads to transfer: Rethinking mechanisms of a neglected phenomenon. Educational Psychologist, 24, 113-142.

Sapp, M. (1994). The effects of guided imagery on reducing the worry and emotionality components of test anxiety. Journal of Mental Imagery, 18, 165-180.

Schmidt, A. M., \& Ford, J. K. (2003). Learning within a learner control training environment: The interactive effects of goal orientation and metacognitive instruction on learning outcomes. Personnel Psychology, 56, 405-429.

Schönpflug, W. (1985). Goal directed behavior as a source of stress: Psychological origins and consequences of inefficiency. In M. Frese \& J. Sabini (Eds.), Goal directed behavior: The concept of action in psychology (pp. 172-188). Hillsdale, NJ: Lawrence Erlbaum Associates.

Schwartz, D. L., \& Bransford, J. D. (1998). A time for telling. Cognition and Instruction, 16, 475-522.

Seijts, G. H., Latham, G. P., Tasa, K., \& Latham, B. W. (2004). Goal setting and goal orientation: An integration of two different yet related literatures. Academy of Management Journal, 47, 227-239.

Simons, P. R., \& De Jong, F. P. C. M. (1992). Self-regulation and computer-aided instruction. Applied Psychology: An International Review, 41, 333-346.

Singer, R. N., \& Pease, D. (1976). A comparison of discovery learning and guided instructional strategies on motor skill learning, retention, and transfer. Research Quarterly, 47, 788-796.

Smith, E. M., Ford, J. K., \& Kozlowski, S. W. J. (1997). Building adaptive expertise: Implications for training design strategies. In M. A. Quinones \& A. Ehrenstein (Eds.), Training for a rapidly changing workplace: Applications of psychological research (pp. 89-118). Washington, DC: American Psychological Association.

Snow, R. E. (1986). Individual differences in the design of educational programs. American Psychologist, 41, 1029-1039.

Spielberger, C. D. (1985). Assessment of state and trait anxiety: Conceptual and methodological issues. Southern Psychologist, 2, 6-16.

Stevens, C. K., \& Gist, M. E. (1997). Effects of self-efficacy and goal-orientation training on negotiation skill maintenance: What are the mechanisms? Personnel Psychology, 50, 955-978. 
Sweller, J. (1988). Cognitive load during problem solving: Effects on learning. Cognitive Science, 12, 257-285.

Sweller, J., Mawer, R., \& Ward, M. (1983). Development of expertise in mathematical problem solving. Journal of Experimental Psychology: General, 112(4), 639-661.

Tabernero, C., \& Wood, R. E. (1999). Implicit theories versus the social construal of ability in self-regulation and performance on a complex task. Organizational Behavior and Human Decision Processes, 78, 104-127.

Tuovinen, J. E., \& Sweller, J. (1999). A comparison of cognitive load associated with discovery learning and worked examples. Journal of Educational Psychology, 91, 334-341.

Volpert, W. (1987). Psychological regulation of work activities. In U. Kleinbeck \& J. Rutenfranz (Eds.), Enzyklopädie der Psychologie: Themenbereich D, Serie III, Band 1. Arbeitspsychologie. Göttingen, Germany: Hogrefe.

Wood, R., \& Bandura, A. (1989). Impact of conceptions of ability on self-regulatory mechanisms and complex decision-making. Journal of Personality and Social Psychology, 56, 407-415.

Wood, R. E., Kakebeeke, B. M., Debowski, S., \& Frese, M. (2000). The impact of enactive exploration on intrinsic motivation, strategy, and performance in electronic search. Applied Psychology: An International Review, 49, 263-283. 